\title{
Building Physics of ETFE-Film Systems
}

\author{
M. Kersken, K. Moritz ${ }^{* *}$, W. Krah ${ }^{*}$, F. Goecke ${ }^{\dagger}$
}

\begin{abstract}
Fraunhofer-Institut für Bauphysik IBP, Fraunhoferstrasse 10, 83626 Valley/Oberlaindern, Germany, e-mail: matthias.kersken@ibp.fraunhofer.de, web page: https://www.ibp.fraunhofer.de/en.html

** Taiyo Europe GmbH, Mühlweg 2, Mühlweg 2, 82054 Sauerlach, Germany, e-mail: k.moritz@taiyo-europe.com,web page: https://taiyo-europe.com/de/

* Dr. Krah \& Partner - Partnerschaft von Sachverständigen und beratendem Ingenieur mbB, Mittelstrasse 5, 96163 Gundelsheim, Germany, e-mail: svkrah@krah-partner.de, web page: https://krah-partner.de/

$\dagger$ se-cover GmbH, Bahnhofstrasse 28, 83119 Obing, Germany, e-mail: florian.goecke@,seele.com web page: https://seele.com/de/
\end{abstract}

\begin{abstract}
Transparent and translucent ETFE films have been used as a component in architecture since the early 1980's. As single-layer structure and as multiple layers air inflated structure, applied in roofs, facades or as a whole building envelope, they have a significant influence on the climatic conditions and the comfort of the enclosed space.

ETFE foil systems used as building envelope have to meet requirements for winter and summer heat protection as well as moisture protection. It is therefore important to know the building physical properties of the film systems and the influencing factors. Depending on the number and spacing of the individual film layers and the installation situation (horizontal, vertical, inclined), the proportions of heat conduction, heat radiation and convection in these systems change. The film layers are usually double-curved, are neither parallel to one another, nor are all surfaces perpendicular to the solar radiation at the same time. The building physics of such systems is very complex, therefore. In the absence of a material-specific standard, the currently available standards are inevitably used to determine building physical parameters such as U-value and g-value. Since such systems are transparent or translucent, the applied standards are primarily related to glass or windows. It should be noted, however, that ETFE foils (depending on the intensity of their printing) are more permeable to radiation in the infrared spectrum than glass. This is an essential difference, since glasses are almost opaque in this spectrum $(5-50 \mu \mathrm{m})$. It means that the applicability of certain existing standards has not been validated so far. In that sense it is an open question if they can be used or if adaptions are required. This applies in particular to the determination of the standardized heat transfer coefficient (U-value $\left.\left[\mathrm{W} /\left(\mathrm{m}^{2} \mathrm{~K}\right)\right]\right)$ which is used to compare different building elements.

The article presents the principle influences on the heat transport mechanisms in ETFE film systems and elaborates on differences in heat transfer coefficients that were determined using different calculation methods (standards) and different boundary conditions.
\end{abstract}

